\title{
A Way to Win: Incentivizing Engineering Faculty to Incorporate Entrepreneur- ship in Their Courses
}

\section{Dr. Adam R. Carberry, Arizona State University}

Dr. Adam Carberry is an associate professor at Arizona State University in the Fulton Schools of Engineering, The Polytechnic School. He earned a B.S. in Materials Science Engineering from Alfred University, and received his M.S. and Ph.D., both from Tufts University, in Chemistry and Engineering Education respectively. Dr. Carberry was previously an employee of the Tufts' Center for Engineering Education \& Outreach.

\section{Dr. Samantha Ruth Brunhaver, Arizona State University, Polytechnic campus}

Samantha Brunhaver is an Assistant Professor of Engineering in the Fulton Schools of Engineering Polytechnic School. Dr. Brunhaver recently joined Arizona State after completing her M.S. and Ph.D. in Mechanical Engineering at Stanford University. She also has a B.S. in Mechanical Engineering from Northeastern University. Dr. Brunhaver's research examines the career decision-making and professional identity formation of engineering students, alumni, and practicing engineers. She also conducts studies of new engineering pedagogy that help to improve student engagement and understanding.

\section{Dr. Jeremi S. London, Arizona State University, Polytechnic campus}

Dr. Jeremi London is an Assistant Professor of Engineering at Arizona State University in the Polytechnic School. London is a mixed methods researcher with interests in research impact, cyberlearning, and instructional change in STEM Education. Prior to ASU, London worked at the National Science Foundation, GE Healthcare, and Anheuser-Busch. She earned B.S. and M.S. degrees in Industrial Engineering, and a Ph.D. in Engineering Education from Purdue University. 


\title{
A Way to Win: Incentivizing Engineering Faculty to Incorporate Entrepreneurship in their Courses
}

\begin{abstract}
It can be very challenging to incentivize engineering faculty to incorporate something new within their courses, labs or programs. Most faculty have the difficult task of balancing their teaching, research and service efforts, which can cause some to be risk averse at times or unwilling to change if what they think they are doing is effective. This can be frustrating for engineering programs, especially when new concepts need to be embedded. Entrepreneurship is a concept that has recently seen a huge uptick in incorporation within engineering programs. Many instances of incorporation have spurred change and have encouraged students to use an Entrepreneurial Mindset (EM) when faced with new challenges. The following study looks at a an internal, competitive professorship opportunity at one institution intended to support the inclusion of EM within engineering courses, labs, and programs. The analysis focuses on faculty awardees and their motivations linked to this opportunity. An assessment is presented looking at the types of projects proposed, how EM was incorporated, when the idea was first conceived, how many times an individual faculty member applied, motivation to apply, and the role of funding in the actual implementation of the project.
\end{abstract}

\section{Introduction}

Changing engineering faculty practices in classrooms, labs and programs is challenging and an ongoing undertaking within engineering units [1-2]. A major reason for the challenge is the reluctance of faculty to change if what they are doing is familiar and seems to be "working." Difficulties associated with change are faculty's readiness, preparation and willingness to take a risk [3-4]. Entrepreneurship is a recent example of a concept that has enacted much change within engineering and engineering education. This confluence of factors calls for an innovative approach to spur change among faculty.

Several engineering faculty at a large, public, southwestern research-focused institution, including tenured and tenure-track faculty, lecturers and adjunct instructors, submitted individual or joint proposals to an internal solicitation for a competitive professorship to embed Entrepreneurial Mindset (EM) into a course, lab or program. The institutional objectives include eight design aspirations; one of which is to value entrepreneurship by using its knowledge and encouraging innovation. The solicitation has been offered each semester for the past four semesters. Proposals are four pages and include information about how the project would embed EM and who would benefit. The winners are awarded funding (up to $\$ 12,000$; provided by the Kern Family Foundation) to support semester-long efforts to develop, implement, and disseminate their EM innovation. A kickoff lunch is held near the beginning of each award 
period to orient winners to the program. Winners additionally receive publications, materials and invitations to workshops and events, to facilitate their EM efforts. Evaluative surveys and interviews are periodically conducted with winners and their students, to monitor and assess the progress of these efforts.

Projects incorporated EM in a variety of ways, including combining EM with an engineering topic or discipline, leveraging EM to enhance student understanding of innovation and entrepreneurship, developing EM to prepare students for their future careers, and improving diversity and inclusion. These efforts were undertaken within the contexts of humanitarian engineering, learning and educational technologies, design, robotics, biomedical engineering, solar power, innovation, smart cities, biomimicry, embedded systems, grand challenges, diversity $\&$ inclusion, and statistics. Awardees were allowed to propose uses for their awarded budget.

The purpose of this study is not to study the efficacy of the competition, but rather to investigate the ways in which the internal competition motivated faculty to make a change. This paper presents insights from awardees regarding their awarded efforts to to embed EM within the context of a course, lab or program.

\section{Theoretical Lens}

Known motivators of faculty change were adopted as the lens for this study. Wergin [5] identified autonomy, recognition, community, and efficacy as critical to motivating faculty to implement changes to their teaching practices. Faculty were found to be more likely to make changes if they were able to work on a problem that interested them, received acknowledgement for their efforts, could work within a community of other scholars, and felt able to make a positive impact. Additional studies using motivational frameworks, including Expectancy-Value [6-7] and Motivational Systems [8], similarly identified perceived importance, enjoyment, benefit, relative cost, goals, resources, and skill development as areas or influencers on whether faculty would engage in change efforts.

The professorship at the center of this paper was designed to encapsulate each of these principles. Faculty develop their own proposals for incorporating EM into a course, lab, or program, which they submit individually or collaboratively. Those awarded the professorship receive funding and support to implement their idea. They are also recognized at the collegelevel as leaders of engineering entrepreneurship education, and both the faculty and their initiative are predominantly featured in internally and externally facing print and web publications throughout the grant period and beyond. The professorship begins and ends, respectively, with a formal orientation session and a celebratory awards ceremony. Resources and information about how faculty can create and deliver EM content to their students and other faculty are shared throughout. 
How much faculty members resonate with the various components of the professorship is unknown. This study takes an in vivo approach to understanding which features of the program faculty find most attractive, i.e., what motivates their interest to apply. This knowledge is anticipated to be useful to universities, federal agencies, foundations, and other funding organizations as they develop new initiatives to spark innovation in higher education.

\section{Methods}

\section{Sample}

The sample for this study consisted of engineering faculty who applied and were awarded an internal competitive professorship grant to embed EM into a course, lab or program. There have been four requests for proposals (RFP) to apply for the professorship - Fall 2016, Spring 2017, Fall 2017 and Spring 2018. It is important to note that the receipt of an award in a given or prior year did not disqualify them from receiving another award, i.e., it is possible for someone to apply for (and receive) more than one award within and across funding cycles. Awardees from all four opportunities were solicited to participate in this study. A total of 33 faculty were contacted; in some instances faculty were single investigators, while others involved faculty collaborating on a single project. A total of 26 responses were initiated from the original inquiry. Incomplete responses were removed from analysis leaving a sample of 19 awardees (58\% response rate).

\section{Data Collection \& Analysis}

Data was collected using a short survey primarily consisting of two close-ended questions number of times applied for the professorship and when the idea was first conceived (i.e., before or after the announcement of the professorship opportunity) - and four open-ended questions title of the project, how EM was incorporated, what aspect of the competition motivated them to apply (e.g., financial support, recognition, etc.), and the role of funding in the actual implementation of their project. Close-ended questions were tabulated and analyzed to demonstrate descriptive statistics. A thematic analysis approach was used for the of open-ended survey responses [9]. Each open-ended question was independently coded by three reviewers. Emergent codes from each question for each reviewer were discussed and agreed upon to achieve $100 \%$ interrater reliability.

\section{Results}

The findings of this study provide insights into what kinds of incentives can serve as beneficial approaches to embedding a specific learning objective, EM, within a course, lab or program. The majority of the survey participants applied once (63\%) (Table 1). Most of the survey participants received one award (68\%); only one out of 19 received more than two awards (Table 2). 
Participants were almost equally split between having the idea they proposed before the RFP (53\%) and coming up with the idea after the RFP (47\%) (Table 3).

Table 1. Survey responses regarding number of applications

\begin{tabular}{|l|c|c|}
\hline How many times have you applied for a professorship? \\
\hline Number of Application Submissions & Frequency & Percentage \\
\hline Applied Once & 12 & $63 \%$ \\
\hline Applied Twice & 4 & $21 \%$ \\
\hline Applied Three Times & 3 & $16 \%$ \\
\hline
\end{tabular}

Table 2. Survey responses regarding number of awards received

\begin{tabular}{|l|c|c|}
\hline How many professorship awards have you received? \\
\hline Number of Awards Received & Frequency & Percentage \\
\hline One Award & 13 & $68 \%$ \\
\hline Two Award & 5 & $26 \%$ \\
\hline More than Two Awards & 1 & $5 \%$ \\
\hline
\end{tabular}

Table 3. Timing of professorship award ideation

\begin{tabular}{|c|c|c|}
\hline \multicolumn{3}{|c|}{$\begin{array}{l}\text { Which of the following scenarios best depicts the point at which you first conceived of you } \\
\text { idea? }\end{array}$} \\
\hline Scenario & Frequency & Percentage \\
\hline $\begin{array}{l}\text { I had an idea that I proposed before learning } \\
\text { about the professorship }\end{array}$ & 10 & $53 \%$ \\
\hline $\begin{array}{l}\text { I didn't come up with my idea until after } \\
\text { learning about the professorship }\end{array}$ & 9 & $47 \%$ \\
\hline
\end{tabular}

Faculty motivations for applying to the RFP are summarized in Table 4. A majority of faculty listed more than one reason for applying (79\%). The most prevalent reasons for applying were an interest in infusing EM into the proposed activity (58\%), a desire for funding to offset the costs of implementing the proposed activity (42\%), and a desire to advance the academic and professional development of the students participating in the proposed activity (32\%). A sample of motivations provided by faculty follows:

"I was already scheduled to create/teach the new [course], but the professorship allowed me to "think bigger" in terms of student resources and projects. The infusion of EM content [and] principles also helped to connect students with a principled and practical 
way of thinking about designing and learning." (coded for infusion of EM, funding, and continue previous efforts)

"I was motivated to apply for the [professorship] because it would afford me the opportunity to integrate learning methods into my classroom that I would have otherwise not been able ... I was also excited to apply to become part of a community of faculty looking for ways to advance their current pedagogical methods through an integrated focus on fostering the entrepreneurial mindset." (coded for infusion of EM, student development, course innovation, and recognition)

"Four mini-projects were added to my [course] for the first time in the Spring 2016 semester to ensure that students understood the relevance of [subject] to their discipline, career, and the world. Doing so led to excellent student outcomes, but it required to a significant increase in the time I spent mentoring teams and grading projects for the class of 50+ students. In light of this, my primary motivations for applying was the secure funding to hire students that work as project mentors/save some of my time. Additionally, I wanted funding to cover the cost of materials needed for the student projects." (coded for funding and student development)

Table 4. Frequency of codes related to motivation

\begin{tabular}{|l|c|c|}
\hline What were your motivations to apply to the professorship? \\
\hline Code & Frequency & Percentage \\
\hline infusion of EM & 11 & $58 \%$ \\
\hline funding & 8 & $42 \%$ \\
\hline student development & 6 & $32 \%$ \\
\hline continue previous efforts & 5 & $26 \%$ \\
\hline course innovation & 4 & $21 \%$ \\
\hline recognition & 3 & $16 \%$ \\
\hline collaboration & 2 & $11 \%$ \\
\hline inspired by previous recipient & 2 & $11 \%$ \\
\hline advance strategic mission & 1 & $5 \%$ \\
\hline community impact & 1 & $5 \%$ \\
\hline
\end{tabular}

A handful of faculty applied to continue a previous or ongoing course effort (26\%) or to start a new course innovation (21\%). Four out of five faculty who reported continuing a course effort also reported that they "had an idea that [they] proposed before learning about the [professorship]." All four faculty who reported wanting to implement a new innovation "didn't 
come up with [their] idea until after learning about" the program. Other faculty reported recognition (16\%), collaboration (11\%), inspiration from a previous recipient $(11 \%)$, desire to help advance the strategic mission of the university (5\%), desire to have a positive impact on the community (5\%), and financial compensation (5\%) as reasons to apply.

Most reasons faculty listed map to known drivers of motivation including funding/resources (benefit), recognition (importance), and enjoyment in trying new things in the classroom or benefiting others (interest) [5]. Other reasons appeared to be more complex. Motivations to contribute to student development, course innovation, or the strategic mission of the university could be grounded in intrinsic interest, but could also be seen by the faculty member as a way to advance their own prestige or productivity. One faculty member wished to use EM to help train students to become better and more entrepreneurial undergraduate and graduate researchers; an idea he described as a "win-win-win situation" for students, faculty, and industry. Similarly, the desire to collaborate could be linked to both enjoyment working with other people and a desire to form stronger partnerships within the university. Understanding the motivations of faculty to apply to the professorship in finer detail is an opportunity for future work.

The role of funding in each faculty member's proposed activity can be seen in Table 5 . Equipment (42\%), project supplies (42\%), and student workers (42\%) were among the most requested resources. Faculty asked for a range of hardware and software, including 3D printers, hand tools, computers and computer programs, textbooks, and audio/video equipment to document the proposed activity. Materials with which students could prototype and develop new ideas were also sought. Student workers were requested to assist with both implementation and assessment (through coaching, or data collection and analysis) of the proposed activity. Other requested resources were more unique to individual faculty. Some faculty used, or intended to use, their funding to cover the costs (e.g., travel, honoraria) of guest speakers $(16 \%)$ or networking events (11\%) in their classes. Additional faculty applied the funding toward travel, so that they $(16 \%)$ or their students $(11 \%)$ could share their innovation at an educational or disciplinary conference. Few faculty applied the funding toward salary (11\%) to compensate themselves for time spent developing or analyzing student outcomes from the proposed activity.

Table 5. Frequency of codes related to funding 


\begin{tabular}{|c|c|c|}
\hline \multicolumn{3}{|c|}{$\begin{array}{l}\text { How have (or how will) you use the professorship to support your innovation, i.e., what did } \\
\text { you include in your budget? }\end{array}$} \\
\hline Code & Frequency & Percentage \\
\hline equipment & 8 & $42 \%$ \\
\hline project supplies & 8 & $42 \%$ \\
\hline student workers & 8 & $42 \%$ \\
\hline guest speakers & 3 & $16 \%$ \\
\hline instructor travel & 3 & $16 \%$ \\
\hline instructor salary & 2 & $11 \%$ \\
\hline networking events & 2 & $11 \%$ \\
\hline student travel & 2 & $11 \%$ \\
\hline
\end{tabular}

\section{Conclusions, Implications, and Future Work}

The findings of this study provide insights into what kinds of incentives can serve as beneficial approaches to embedding EM within a course, lab, or program. Nearly half of the faculty came up with the idea they proposed after the funding opportunity became available. The implication is that internal competitions, like the one described in this study, have the potential to spur innovations among faculty or support lingering ideas. Further analysis of future awardees within this program and collaborations with institutions implementing similar programs would provide a broader and more generalizable understanding of internal, competitive professorship opportunities supporting the inclusion of EM within engineering courses, labs, and programs.

The findings also point to the fact that if faculty are given multiple opportunities to apply for funding to do something innovative, some will take advantage of it every time it is available. Programs that decide to implement a model similar to the one described in this study should avoid limiting the number of submissions from a single person and/or disqualifying previous recipients from receiving the award again. An evaluation of the resulting innovations implemented by faculty through the program, including sustainability of new, revised, or modified innovations, should accompany the program to ensure impact beyond the funding period.

Lastly, it is important to highlight the fact that some of the faculty's motivations for seeking funding align with existing literature [6-8, 9-10], but in other cases, the exact drivers motivating faculty to apply were unclear. Future work related to this topic should focus on clearly delineating faculty motivations, including causes and inhibitors, for applying to internal competitions for teaching-related funding. An examination of student motivations would also provide insights into how faculty and students influence and/or reinforce one another. 


\section{Acknowledgement}

This material is based on work supported by The Kern Family Foundation in association with the Kern Entrepreneurial Engineering Network (KEEN).

\section{References}

[1] M. Besterfield-Sacre, M. F. Cox, M. Borrego, K. Beddoes, and J. Zhu, "Changing engineering education: Views of US faculty, chairs, and deans," Journal of Engineering Education, vol. 103, no. 2, pp. 193-219, 2014.

[2] M. Borrego and C. Henderson, "Increasing the use of evidence-based teaching in STEM higher education: A comparison of eight change strategies," Journal of Engineering Education, vol. 103, no. 2, pp. 220-252, 2014.

[3] A. F. McKenna, J. Froyd, and T. Litzinger, "The complexities of transforming engineering higher education: Preparing for next steps," Journal of Engineering Education, vol. 103, no. 2, pp. 188-192, 2014.

[4] National Research Council, A framework for K-12 science education: Practices, crosscutting concepts, and core ideas. Washington, D.C.: National Academies Press, 2012.

[5] J. F. Wergin, "Beyond Carrots and Sticks: What Really Motivates Faculty," Liberal Education, vol. 87, no. 1, pp. 50-53, 2001.

[6] C. J. Finelli, K. M. Richardson, and S. R. Daly, "Factors that influence faculty motivation of effective teaching practices in engineering, in Proceedings of the American Society for Engineering Education Annual Conference \& Exposition, Atlanta, GA, USA, June 23-26, 2013.

[7] H. M. Matusovich, M. C. Paretti, L. D. McNair, and C. Hixson, "Faculty motivation: A gateway to transforming engineering education," Journal of Engineering Education, vol. 103, no. 2, pp. 302-330, 2014.

[8] C. L. Colbeck, A. F. Cabrera, and R. J. Marine, "Faculty motivation to use alternative teaching methods," Paper presented at the Annual Meeting of the American Educational Research Association, New Orleans, LA, USA, April 1, 2002.

[9] M. Miles and M. Huberman, Qualitative data analysis: A source book for new methods. Thousand Oaks, CA: Sage Publications, 1994.

[10] P. L. Hardré, R. B. Miller, A. D. Beesley, T. M. Pace, M. S. Maxwell, and K. Xie, "What motivates university faculty members to do research?: Tenure-track faculty in researchextensive universities," Journal of the Professoriate, vol. 2, no. 1, pp. 75-99, 2007.

[11] P. L. Hardré, A. D. Beesley, R. L. Miller, and T. M. Pace, "Faculty motivation to do research: Across disciplines in research-extensive universities," Journal of the Professoriate, vol. 5, no. 1, pp. 35-69, 2011. 